Belzner, Fabian; Merkel, Jennifer; Gebhardt, Michael; Thorenz, Carsten Piano key and labyrinth weirs at German waterways: recent and future research of the BAW

Originalveröffentlichung / Original Publication:

https://doi.org/10.1201/9781315169064

Verfügbar unter / Available at:

https://hdl.handle.net/20.500.11970/105138

Vorgeschlagene Zitierweise / Suggested citation:

Belzner, Fabian; Merkel, Jennifer; Gebhardt, Michael; Thorenz, Carsten (2017): Piano key and labyrinth weirs at German waterways: recent and future research of the BAW. In: Erpicum, Sébastien; Laugier, Frédéric; Ho Ta Khanh, Michel; Pfister, Michael (Hg.): Labyrinth and Piano Key Weirs III - Proceedings of the 3rd International Workshop on Labyrinth and Piano Key Weirs (PKW 2017), February 22-24, 2017, Qui Nhon, Vietnam. Boca Raton: CRC Press. S. 167-174. 


\title{
Piano Key and Labyrinth Weirs at German waterways: Recent and future research of the BAW
}

\author{
F. Belzner, J. Merkel, M. Gebhardt \& C. Thorenz \\ Federal Waterways Engineering and Research Institute (BAW), Germany
}

\begin{abstract}
The paper provides an overview of model investigations on different geometries of piano key and labyrinth weirs for free and submerged flow conditions. Physical model investigations with different geometries have been carried out. The results indicate that the submergence sensitivity of the rectangular and the trapezoidal labyrinth weir is slightly higher compared to the piano key weir and the triangular labyrinth weir but the triangular labyrinth weir has a lower efficiency. Furthermore a numerical 3D model of the PKW Type A based on the OpenFOAM ${ }^{\circledR}$ software has been used to investigate specific hydraulic aspects and for comparisons with physical model results. The effect of nappe suction and ventilation is influencing the discharge coefficient which leads to significant deviations in the results of the numerical and physical tests especially for small heads.
\end{abstract}

\section{INTRODUCTION}

\subsection{Fixed weirs at Germany waterways}

With a total length of $7350 \mathrm{~km}$, more than 300 weirs and 450 lock chambers Germany has the largest inland waterway network in Western Europe. Every year up to 240 million tons of cargo are transported on these waterways and about 400,000 jobs depend directly or indirectly on the inland navigation.

The inland waterways can roughly be divided in two categories: On the one hand the so-called core network including the rivers Rhine, Moselle or the Middleland canal with a significant amount of cargo (about $4000 \mathrm{~km}$ waterways) and on the other hand second-grade rivers and channels like the Ilmenau River or the Finow Canal with negligible commercial navigation. Most of them are nowadays used only for recreational purposes with pleasure boats. Until today there are roughly 100 weirs in operation to satisfy existing water level requirements. A major part has to be replaced within the next years.

Due to flood prevention and the interests of other stakeholders the impoundments cannot be given up, but the requirements concerning the minimum and maximum water levels can be reduced and a greater variability can be accepted. Currently, there are considerations to replace movable weirs outside of the core network by fixed weirs to reduce operation and maintenance costs. Therefore, established weir types like side weirs or newer developments like labyrinth weirs and piano key weirs are in consideration. Currently, the Federal Waterways Engineering and Research Institute (BAW) is conducting studies to check the suitability of these fixed weirs and to provide hydraulic fundamentals for developing standard solutions for the waterway network. First results were presented in Belzner et al. (2016), a possible application is described in Gebhardt et al. (2017).

\subsection{General considerations}

Discharge over a control structure can occur as free flow or submerged flow. Free flow occurs when the upstream water level only depends on the geometry of the control structure and the discharge. In this case, the discharge $\mathrm{Q}\left[\mathrm{m}^{3} / \mathrm{s}\right]$ can be described by the formula from Du Buat 


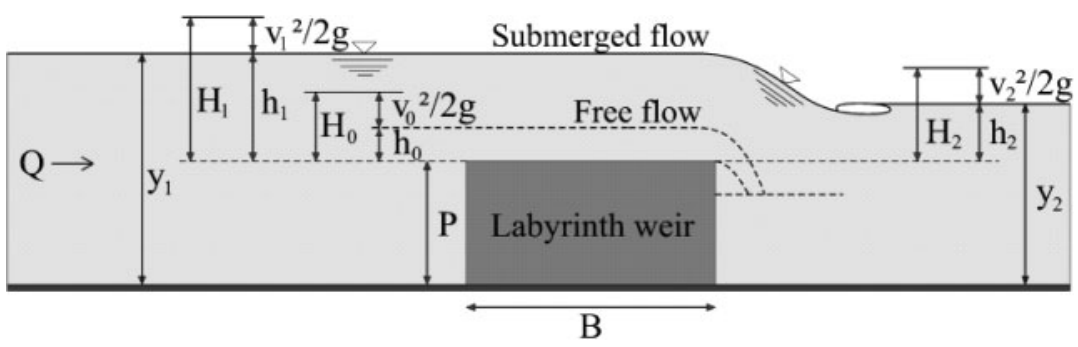

Figure 1. Definition Sketch.

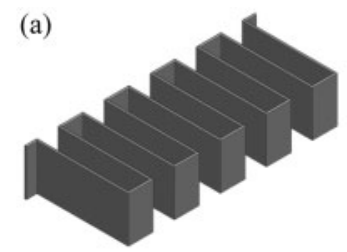

(d)

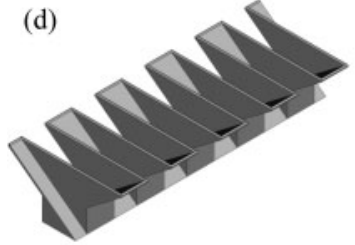

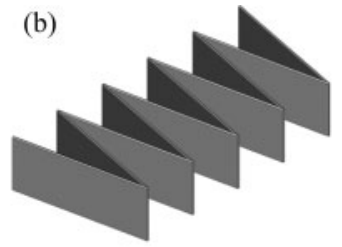

(e)

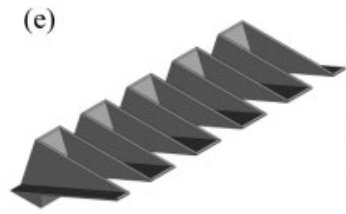

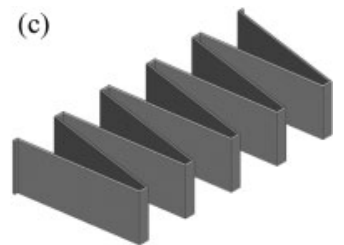

(a) Rectangular labyrinth weir

(b) Triangular labyrinth weir

(c) Trapezoidal labyrinth weir

(d) Piano key weir type A

(e) Piano key weir type C

Figure 2. Piano key weir and labyrinth weir geometries.

(Eq. 1) depending on a non-dimensional discharge coefficient $\mathrm{C}_{\mathrm{d}}[-]$, the upstream head $\mathrm{H}_{0}[\mathrm{~m}]$ and the total width $\mathrm{W}[\mathrm{m}]$ :

$$
\mathrm{Q}_{\text {free }}=\frac{2}{3} \cdot \mathrm{C}_{d} \cdot \mathrm{W} \cdot \sqrt{2 \mathrm{~g}} \cdot \mathrm{H}_{0}^{3 / 2}
$$

Raising the downstream water level $\mathrm{h}_{2}[\mathrm{~m}]$ at constant discharge $\mathrm{Q}$, the upstream head $\mathrm{H}_{0}$ also rises and becomes a function of the discharge coefficient $\mathrm{C}_{\mathrm{d}}$ and the downstream head $\mathrm{H}_{2}[\mathrm{~m}]$. In addition to the parameters given in Figure 1, the clear width is described as $\mathrm{W}[\mathrm{m}]$ and the developed crest length as $\mathrm{L}[\mathrm{m}]$.

\subsection{Labyrinth and piano key weirs}

According to Eq. 1, the discharge over a weir at a constant head $\mathrm{H}_{0}$ linearly scales with the crest length L: Doubling the overflow length doubles the discharge. Typical applications are side weirs with long crests. Here, the upstream water level variation is lower than for linear weirs. However, due to space requirements side weirs cannot be realized at every site. With a curved or folded overflow crest, a higher hydraulic performance can be achieved at a constant overall width W.

The simplest form of a weir with a folded crest is the labyrinth weir (Figure $2 a$ ), b), c)). Due to its simple geometry it can be easily constructed, but a relatively large footprint is required. A further development of the labyrinth weir is the piano key weir (pkw, Figure $2 \mathrm{~d}$ ), e)), presented by Lempérière and Ouamane in 2003. In contrast to labyrinth weirs, the upstream and downstream walls are inclined inwards which reduces the footprint significantly. Therefore, the piano key weir is particularly suitable for large concrete dams, where the available space is limited by the crown width.

In recent years, the research on labyrinth and piano key weirs noticeable increased mainly due to new design floods for large dams. In particular in France the discharge capacity of numerous spillways has been improved by the use of piano key weirs. 


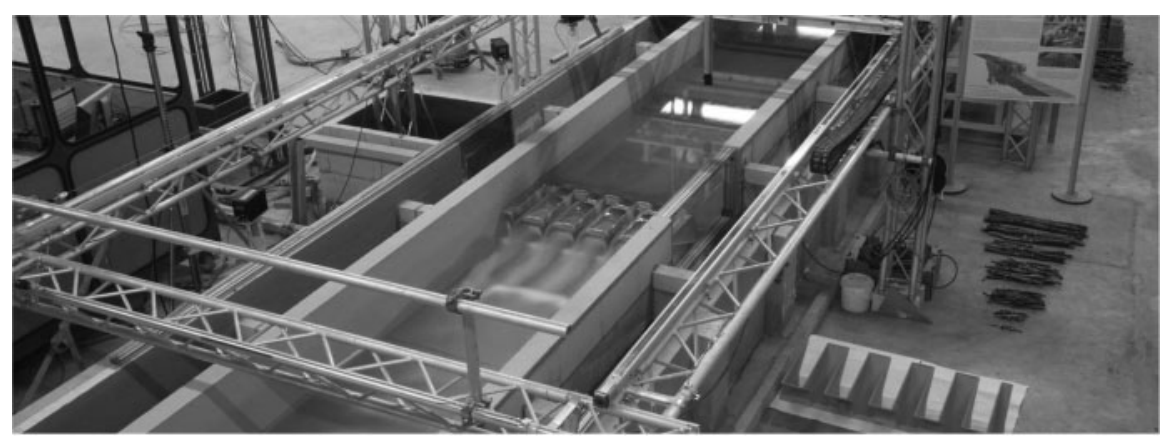

Figure 3. Physical model.

The cyclically repeating units of the piano key weir are called "keys". Inlet-keys are open to the upstream water and outlet-keys are open to the downstream water. The hydraulic capacity of labyrinth and piano key weirs is substantially influenced by its crest length, which is for small heads equal to the overflow length. The hydraulic capacity increases directly proportional with the crest length for small heads (Schleiss, 2011). With increasing upstream head, the effective overflow length gets smaller than the crest length (Falvey, 2003). Furthermore the discharge capacity is influenced by a variety of other parameters, such as the shape of the crest, the length of the keys, the ratio of width of the inlet- and outlet-keys or the inclination of the upstream and downstream walls. Pralong et al. (2011) introduced a naming convention for piano key weirs which can be transferred to labyrinth weirs and is commonly used in the literature relating to these weir types.

Despite of the intensive research and development work in the last years, there is little experience with labyrinth weirs and piano key weirs at rivers where the tailwater level typically increases with the discharge and submerged flow occurs. Thus, the investigations in BAW are not only but mainly focused on the question, whether the hydraulic advantage of folded weirs is still given if submerged flow occurs. For that purpose physical experiments for different geometries (Figure 2) and some comparative numerical calculations were carried out.

\section{EXPERIMENT AND METHODOLOGY}

\subsection{Physical model}

For the physical tests a $1.25 \mathrm{~m}$ wide flume with a length of $15.00 \mathrm{~m}$ and a height of $0.60 \mathrm{~m}$ was used (Figure 3). The measurement of the water levels was carried out by ultrasonic water level probes on measuring containers, which were connected to the flume by the principle of communicating pipes in distances of $1.25 \mathrm{~m}$ to $2.00 \mathrm{~m}$. The measuring error of the water level probes was about $+/-0.1 \mathrm{~mm}$.

In order to allow higher specific discharges a second flume with a length of $18 \mathrm{~m}$, a height of $1.20 \mathrm{~m}$ and a width of $0.60 \mathrm{~m}$ were used. Here, the water level measurements were carried out with manual water level probes.

The discharge in both flumes was controlled by a magnetic-inductive flowmeter (MID) and electrically adjustable valves. The downstream water level was adjusted by a rectangular outlet flap. The upstream water level $\mathrm{y}_{1}[\mathrm{~m}]$ was measured $2.58 \mathrm{~m}$ upstream of the weir, the downstream water level $\mathrm{y}_{2}[\mathrm{~m}] 5.34 \mathrm{~m}$ downstream of the weir.

\subsection{Numerical model}

The numerical simulations were performed with the open source CFD toolbox OpenFOAM ${ }^{\circledR}$ with the two phase transient solver interFoam in version 2.2.2. A detailed description can be found in Rusche (2002). A 3D model with identical dimensions like the $1.25 \mathrm{~m}$ wide flume was created and 
discretized with a hexahedral dominant mesh with a base mesh size of $0.05 \mathrm{~m}$. Areas where smallscale phenomena like flow detachment occur (e.g. the crest) were discretized up to a mesh size of $0.003 \mathrm{~m}$. For turbulence modelling a k-Omega-SST model was used. Three dimensional transient calculations with stationary boundary conditions were conducted until a quasi-stationary state was achieved. A set of in-house developed boundary conditions which are explained in Thorenz and Strybny (2012) were used for the inflow and outflow boundaries. The discharge at the inflow boundary is described by the velocity field depending on the free water surface near the boundary. At the outflow a fixed downstream water level was prescribed via the pressure field for each cell on the boundary depending on the desired water level. For particular cases an artificial aeration was provided by an additional boundary area with a prescribed pressure field at the downstream parapet walls.

\subsection{Test series}

Laboratory tests were performed on five geometries: piano key weir, types A (upstream and downstream overhangs) and $\mathrm{C}$ (only downstream overhangs), and labyrinth weirs with rectangular, trapezoidal and triangular folded sections. For the preliminary design of the piano key weir type A the formulas of Machiels (2013) and Pfister and Schleiss (2013) were used. To reduce the geometric parameters the inlet and outlet key width and length were chosen to be equal $\left(\mathrm{W}_{\mathrm{i}}=\mathrm{W}_{\mathrm{o}}, \mathrm{B}_{\mathrm{i}}=\mathrm{B}_{\mathrm{o}}\right)$. In order to compare the hydraulic capacity of the five weir types, height $(\mathrm{P}=0.253 \mathrm{~m})$, clear width $(\mathrm{W}=1.25 \mathrm{~m})$, crest length $(\mathrm{L} / \mathrm{W}=5)$ and sidewall thickness $\left(\mathrm{T}_{\mathrm{S}}=0.01 \mathrm{~m}\right)$ were identical. Cicero and Delisle (2013b) investigated the influence of different crest geometries on the discharge capacity and recommended a half rounded or quarter rounded crest for small heads up to $\mathrm{H}_{1} / \mathrm{P}<0.3$. This recommendation was adopted for the experiments by using a half rounded crest. In the $1.25 \mathrm{~m}$ wide flume tests with a combination of specific discharges between $0.02 \mathrm{~m}^{3} /(\mathrm{sm})$ and $0.30 \mathrm{~m}^{3} /(\mathrm{sm})$ and downstream water levels between $0.05 \mathrm{~m}$ and $0.50 \mathrm{~m}$ were performed. To generate results for higher floods experiments were conducted in the $0.60 \mathrm{~m}$ wide flume with specific discharges up to $0.70 \mathrm{~m}^{3} /(\mathrm{sm})$. All results shown in this paper are based on physical or numerical experiments.

\section{RESULTS}

\subsection{Free flow}

The discharge coefficient $C_{d}$ was determined according to Eq. 1. As it is common practice, the clear width $\mathrm{W}$ instead of the crest length $\mathrm{L}$ was used. Usually, the clear width is more relevant for the practical planning than the crest length.

Figure 4 shows the discharge coefficient depending on the ratio of the total upstream head $\mathrm{H}_{0}$ to the weir height $\mathrm{P}[\mathrm{m}]$ for the labyrinth weirs. Note, for $\mathrm{H}_{0} / \mathrm{P}>0.75$ only data for the rectangular weir in the $0.60 \mathrm{~m}$ wide flume is shown. For the triangular and trapezoidal weir no data is available yet for higher specific discharges. The efficiency for the rectangular labyrinth weir with $\mathrm{P}=0.210 \mathrm{~m}$ $(\mathrm{W} / \mathrm{P}=0.286)$ and $\mathrm{P}=0.262 \mathrm{~m}(\mathrm{~W} / \mathrm{P}=2.77)$ is nearly the same. Comparing the results for the rectangular weir it can be seen that the discharge coefficient estimated from the experiments in the $0.60 \mathrm{~m}$ wide flume is slightly smaller, probably because of the higher influence of the sidewalls.

In general, the discharge coefficients show for $\mathrm{H}_{0} / \mathrm{P}>0.1$ the same trend. For smaller head ratios a high scatter can be observed. In these tests the upstream total head is small $\left(\mathrm{H}_{0}<0.03 \mathrm{~m}\right)$ and the results could be influenced by surface tension effects described in Pfister, Battisacco et al. (2013). For that reason Ribeiro et al. (2012) considered only test cases with $\mathrm{H}_{0}>0.05 \mathrm{~m}$. It can also be seen that the discharge coefficients for the triangular and the trapezoidal labyrinth weir for $\mathrm{H}_{0} / \mathrm{P}<0.1$ are significantly lower. The results show an overall agreement with Crookston (2010). A comparison is given in Gebhardt et al. (2017).

The lower hydraulic efficiency of the triangular labyrinth weir for small upstream heads can be explained by the dry downstream corners leading to a smaller effective crest length. On the other hand, the highest efficiency could be observed for the trapezoidal labyrinth weir for $\mathrm{H}_{0} / \mathrm{P}>0.1$ 


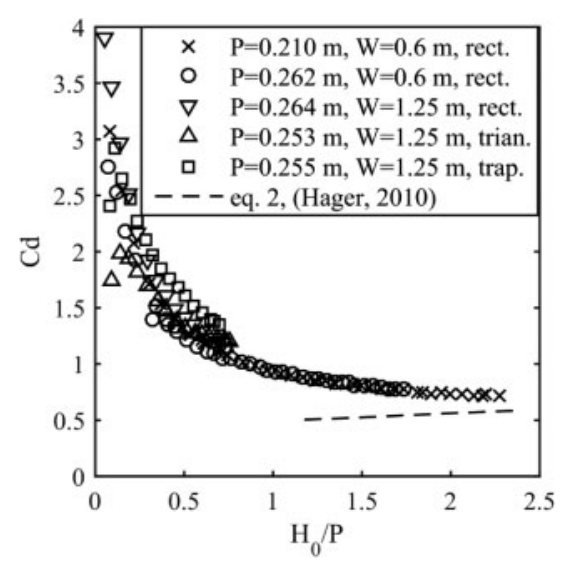

Figure 4. Discharge coefficient $C_{d}$ for labyrinth weirs.

(a)

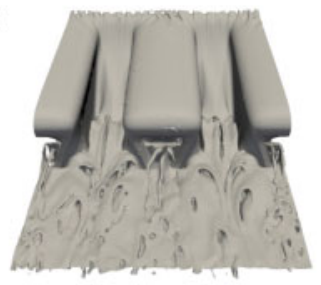

(b)

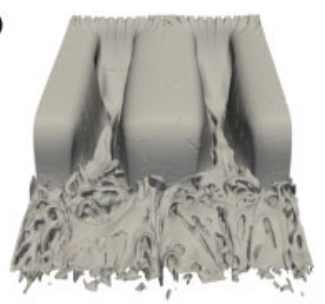

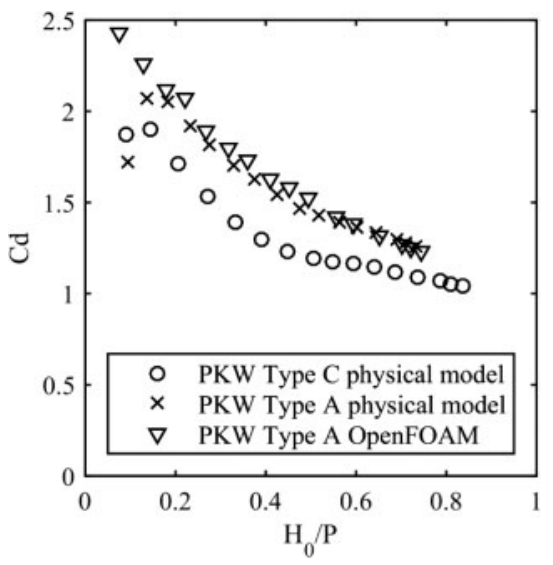

Figure 5. Discharge coefficient $\mathrm{C}_{\mathrm{d}}$ for piano key weirs.

Figure 6. Numerical results for unaerated flow (a) and aerated flow (b) in comparison with physical experiment (c) for $\mathrm{q}=0.04 \mathrm{~m}^{3} /(\mathrm{sm})$.

(Figure 4). Here, the downstream corners are still flow effective and the effect of nappe interference and local submergence is less distinct compared to the rectangular labyrinth weir.

It can also be seen that the discharge coefficient decreases while the upstream head increases and finally approaches the discharge coefficient of a broad-crested weir. The effective length decreases like it is described in Falvey (2003). For comparison, Figure 4 shows also the results of Hager's equation for the broad-crested weir (Hager, 2010). Due to different definitions of $C_{d}$, the values by Hager's equation were divided by a factor of $2 / 3$ in order to correspond with Eq. 1 .

Figure 5 shows the discharge coefficients for the physical and the numerical model of the piano key weir. Comparing type $\mathrm{A}$ and type $\mathrm{C}$ in the physical model, the discharge coefficients of type $\mathrm{A}$ are higher. The nearly vertical upstream walls of type $\mathrm{C}$ cause a strong bending of the streamlines and thus higher energy losses.

For validation purposes, numerical tests with the piano key weir type A were conducted and compared with the results of the physical model tests. Neither in the physical nor in the numerical test series an external aeration was provided. Both methods lead to similar results for $\mathrm{H}_{0} / \mathrm{P}>0.15$. The discharge coefficient obtained in the physical tests for smaller head ratios $\left(\mathrm{H}_{0} / \mathrm{P}<0.15\right)$ is smaller compared to the coefficient obtained in the numerical tests. Pfister, Battisacco et al. (2013) describe an underestimation of the discharge coefficient in the physical model for small heads due to onset of flow and surface tension effects. In the numerical simulations the nappe attaches to the structure for small heads $\left(\mathrm{H}_{0} / \mathrm{P}<0.15\right)$ for the unaerated case (Figure 6 a) and separates if aeration is provided (Figure $6 \mathrm{~b}$ ). For $\mathrm{q}=0.04 \mathrm{l} / \mathrm{s}$ there was no difference in $\mathrm{C}_{\mathrm{d}}$ between aerated and unaerated flow. In the physical model the nappe was attached for $\mathrm{H}_{0} / \mathrm{P}=0.10$ and separated for $\mathrm{H}_{0} / \mathrm{P}=0.14$ (Figure $6 \mathrm{c}$ ). The shape of bending streamlines and the effects of nappe suction 


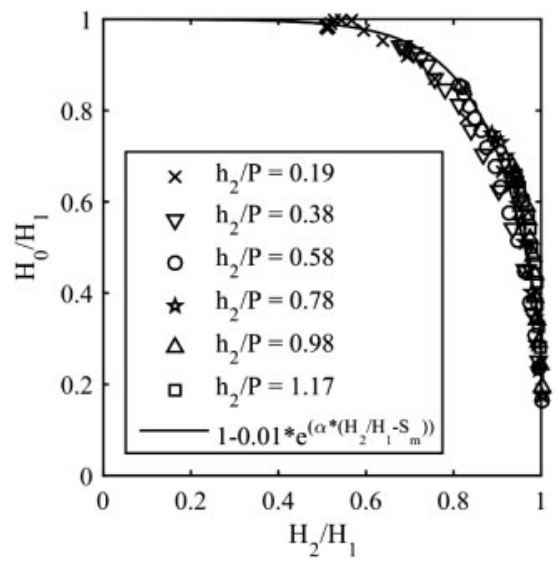

Figure 7. Submergence sensitivity for pkw type A.

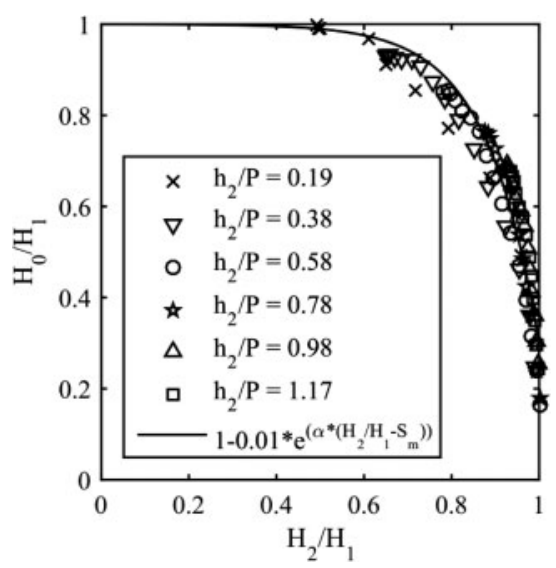

Figure 8. Submergence sensitivity for triangular labyrinth weir.

and nappe ventilation are influencing the discharge coefficient. It is difficult to simulate both in physical and numerical models in a similar way. Furthermore, small errors in the determination of $\mathrm{h}_{0}$ lead to significant deviations in in the discharge coefficient, so that the determination of $\mathrm{C}_{\mathrm{d}}$ is not trivial for very small heads.

\subsection{Submerged flow}

Raising the downstream water level above a certain value affects the flow and $h_{1}$ is no longer independent of $h_{2}$. This transition between free and submerged flow is called the "modular limit" (Hager, 2010). For comparison: The modular limit for a broad crested weir is $h_{2} / h_{1}=0.80$ to 0.85 , for an embankment weir $\mathrm{h}_{2} / \mathrm{h}_{1}=0.75$ (Fritz \& Hager, 1998) and for a sharp crested weir $\mathrm{h}_{2} / \mathrm{h}_{1}=0.65$ (Hager, 2010). Sharp crested weirs are more vulnerable to backwater effects, because due to the curved streamlines in the control section the horizontal momentum is smaller than for broad crested weirs.

In Cicero and Delisle (2013a) the modular limit $S_{m}$ was determined for different piano key weir types. They expressed the backwater effect as the ratio of the total upstream head for free flow $\mathrm{H}_{0}$ to the total upstream head $\mathrm{H}_{1}$. For $\mathrm{H}_{0} / \mathrm{H}_{1}=1$ the upstream head $\mathrm{H}_{1}$ equals the head for free flow $\mathrm{H}_{0}$ and is independent of $\mathrm{H}_{2}$. We followed this methodology in Figures 7-10 though we think that $\mathrm{h}_{2}$ would be the more relevant parameter. In Figure 7 and Figure 8 the influence of the rising downstream water level $\mathrm{h}_{2}$ (and thus the downstream head $\mathrm{H}_{2}$ ) on the upstream head is noticeable for the piano key weir and the triangular labyrinth weir for $\mathrm{H}_{2} / \mathrm{H}_{1}=0.5$. With increasing submergence, the upstream head increases and $\mathrm{H}_{0} / \mathrm{H}_{1}$ decreases. Figure 7 shows a comparison of the test data with the formula of Cicero and Delisle (2013a) for the piano key weir type A. It can be seen, that there is a good agreement for $\alpha=8.50$ and $\mathrm{S}_{\mathrm{m}}=0.50$. A good correlation $(\mathrm{R}>0.98)$ can also be achieved for the triangular labyrinth weir for $\alpha=8.39$ and $\mathrm{S}_{\mathrm{m}}=0.49$ (Figure 8).

Figure 9 and Figure 10 show the submergence ratio for the trapezoidal respectively the rectangular labyrinth weir. In the results a high dependence on the tailwater ratio $\mathrm{h}_{2} / \mathrm{P}$ can be seen. Comparing the results for the four different geometries this effect is not noticeable in the piano key weir results, hardly existing in the results for the triangular labyrinth weir and distinct at the trapezoidal and rectangular labyrinth weir. It is triggered by the interaction of nappes and local submergence effects which were described by Crookston and Tullis (2012). Herein, the labyrinth weir has a disadvantage: The nappe at a piano key weir falls on an inclined downstream wall and a jet is deflected in flow direction. In contrast, the nappe at a labyrinth weir falls on a flat surface, energy dissipates and the jet loses its vertical momentum. Thus, the water level in the outlet key rises. This effect can be reduced by an expansion of the keys in flow direction, like it exists e.g. at triangular or trapezoidal 


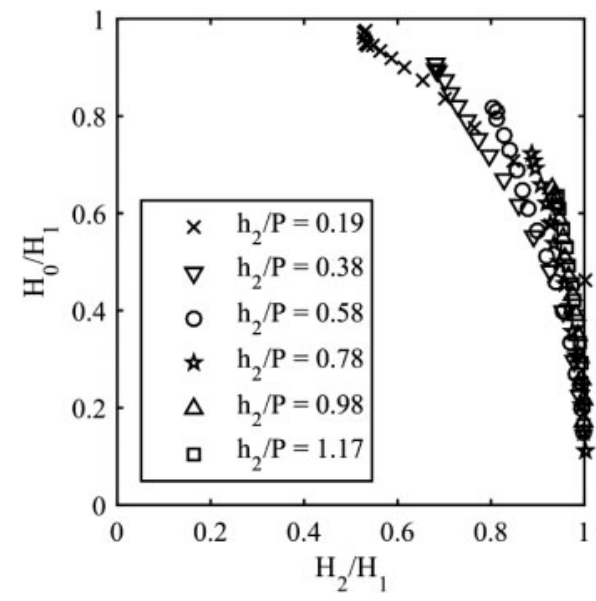

Figure 9. Submergence sensitivity for trapezoidal labyrinth weir.

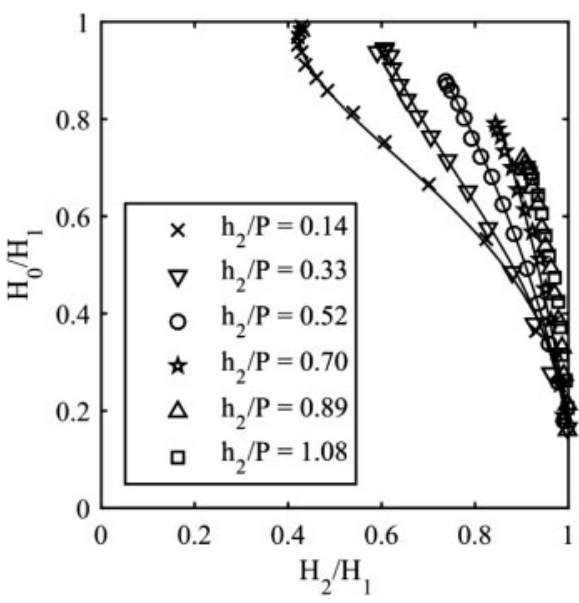

Figure 10. Submergence sensitivity for rectangular labyrinth weir.

labyrinth weirs or a sloped bottom surface. Reducing the flow velocity and thus the energy losses, this expansion is advantageous for the outflow of the keys.

\section{CONCLUSION AND OUTLOOK}

Five different folded weir types were investigated with physical and numerical models under boundary conditions which are typical for water level controlled rivers: The downstream water level rises with increasing discharge, so that often submerged flow occurs for the design flood of the weir. The results indicate that the submergence sensitivity of the rectangular and the trapezoidal labyrinth weir is slightly higher compared to the piano key weir and the triangular labyrinth weir but the triangular labyrinth weir has a lower efficiency.

One of the major advantages of piano key weir is the small footprint in flow direction which allows constructing it on limited space. Against that the labyrinth weir is easier to construct due to the vertical walls. There are few space limitations on the German inland waterways and no requirements to small footprints exist. So, for practical purposes, it has to be considered, if the hydraulic disadvantage of the labyrinth weir under submerged conditions can be accepted in favor of the simpler construction.

Nevertheless there are many open questions concerning the suitability of labyrinth and piano key weirs for federal waterways. The effect of driftwood on piano key weirs is described in Pfister, Schleiss et al. (2013) for the piano key weir for floating wood. In reservoirs diving wood does not affect the efficiency because it sinks down to the bed. But, in rivers it can accumulate in front of the weir and reduce the discharge coefficient. Furthermore the effect of bedload in the keys of labyrinth weirs and the bedload transport capacity has to be investigated. Crookston and Tullis (2012) mentioned, that the degree to which experimentally determined $C_{d}$ data for one labyrinth weir geometry can be applied to one that is geometrically comparable is unknown. Hence, the BAW is currently conducting experiments with different weir heights to be able to estimate the applicability of recent results for other weir sizes with the same water level ratios.

\section{ACKNOWLEDGMENTS}

The authors thank the students Kristina Heveling, Larissa Rihm, Laura Kesper, Alexander Leitz and Waldemar Braun for spending many hours in the laboratory and for their excellent support 
during the model tests. Mr. Udo Pfrommer provided support and equipment and enabled a smooth running of the laboratory.

\section{REFERENCES}

Belzner, F., Merkel, J., Pfrommer, U., Gebhardt, M. \& Thorenz, C. (2016) Piano-Key-Wehre und LabyrinthWehre unter den Randbedingungen einer Bundeswasserstraße. Wasserwirtschaft, (5), 37-42.

Cicero, G. \& Delisle, J. (2013a) Discharge characteristics of Piano Key weirs und submerged flow. In: Erpicum, S., Laugier, F., Pfister, M., Pirotton, M., Cicero, G.-M. \& Schleiss, A.J. (eds.) Labyrinth and Piano Key Weirs II: CRC Press/Balkema. pp. 101-109.

Cicero, G. \& Delisle, J. (2013b) Effects of the crest shape on the discharge efficiency of a type A Piano Key weir. In: Erpicum, S., Laugier, F., Pfister, M., Pirotton, M., Cicero, G.-M. \& Schleiss, A.J. (eds.) Labyrinth and Piano Key Weirs II: CRC Press/Balkema. pp. 41-48.

Crookston, B.M. (2010) Labyrinth Weirs. Logan.

Crookston, B.M. \& Tullis, B.P. (2012) Labyrinth Weirs: Nappe Interference and Local Submergence. Journal of Irrigation and Drainage Engineering. [Online] 138 (8), 757-765. Available from doi:10.1061/ (ASCE)IR.1943-4774.0000466.

Falvey, H.T. (2003) Hydraulic design of labyrinth weirs. Reston, Va, ASCE Press (American Society of Civil Engineers).

Fritz, H.M. \& Hager, W.H. (1998) Hydraulics of Embankment Weirs. Journal of Hydraulic Engineering. [Online] 124 (9), 963-971. Available from doi:10.1061/(ASCE)0733-9429(1998)124:9(963).

Gebhardt, M., Merkel, J., Belzner, F. \& Thorenz, C. (2017) A comparison of side weirs and labyrinth weirs at Ilmenau River (accepted). In: Erpicum, S., Laugier, F., Pfister, M., Pirotton, M., Cicero, G.-M. \& Schleiss, A.J. (eds.) Labyrinth and Piano Key Weirs III: CRC Press/Balkema.

Hager, W.H. (2010) Wastewater hydraulics: Theory and practice. 2nd edn. Berlin, London, Springer.

Lempérière, F. \& Ouamane, A. (2003) The Piano Keys Weir: a new cost-effective solution for spillways. Hydropower and Dams, 144-149.

Machiels, O. (2013) An analytical approach for Piano Key weir hydraulic design. In: Erpicum, S., Laugier, F., Pfister, M., Pirotton, M., Cicero, G.-M. \& Schleiss, A.J. (eds.) Labyrinth and Piano Key Weirs II: CRC Press/Balkema. pp. 131-138.

Pfister, M., Battisacco, E., De Cesare, G. \& Schleiss, A. (2013) Scale effects related to the rating curve of cylinidrically crested Piano Key weirs. In: Erpicum, S., Laugier, F., Pfister, M., Pirotton, M., Cicero, G.-M. \& Schleiss, A.J. (eds.) Labyrinth and Piano Key Weirs II: CRC Press/Balkema. pp. 73-82.

Pfister, M. \& Schleiss, A. (2013) Estimation of A-type Piano Key weir rating curve. In: Erpicum, S., Laugier, F., Pfister, M., Pirotton, M., Cicero, G.-M. \& Schleiss, A.J. (eds.) Labyrinth and Piano Key Weirs II: CRC Press/Balkema. pp. 139-147.

Pfister, M., Schleiss, A.J. \& Tullis, B.P. (2013) Effect of driftwood on hydraulic head of Piano Key weirs. In: Erpicum, S., Laugier, F., Pfister, M., Pirotton, M., Cicero, G.-M. \& Schleiss, A.J. (eds.) Labyrinth and Piano Key Weirs II: CRC Press/Balkema. pp. 255-264.

Pralong, J., Vermeulen, J., Blancher, B., Laugier, F., Erpicum, S., Machiels, O., Pirotton, M., Boillat, J.-L., Ribeiro, M.L. \& Schleiss, A. (2011) A naming convention for the Piano Key Weirs geometrical parameters. In: Erpicum, S., Laugier, F., Boillat, J.-L., Pirotton, M., Reverchon, B. \& Schleiss, A. (eds.) Labyrinth and Piano Key Weirs: Boca Raton, CRC Press/Balkema. pp. 271-278.

Ribeiro, M.L., Pfister, M., Schleiss, A.J. \& Boillat, J.-L. (2012) Hydraulic design of A-type Piano Key Weirs. Journal of Hydraulic Research. [Online] 50 (4), 400-408. Available from doi:10.1080/00221686.2012. 695041.

Rusche, H. (2002) Computational Fluid Dynamics of Dispersed Two-Phase Flows at High Phase Fractions. [Online]. London. Available from: http://powerlab.fsb.hr/ped/kturbo/OpenFOAM/docs/HenrikRuschePhD 2002.pdf [Accessed 19th August 2016].

Schleiss, A.J. (2011) From Labyrinth to Piano Key Weirs - A historical review. In: Erpicum, S., Laugier, F., Boillat, J.-L., Pirotton, M., Reverchon, B. \& Schleiss, A. (eds.) Labyrinth and Piano Key Weirs: Boca Raton, CRC Press/Balkema. pp. 3-15.

Thorenz, C. \& Strybny, J. (2012) On the numerical modelling of filling-emptying systems for locks. In: Hinkelmann, R., Liong, Y., Savic, D., Nasermoaddeli, M.H., Daemrich, K.-F., Fröhler, P. \& Jacob, D. (eds.) Proceedings of 10th International Conference on Hydroinformatics: Understanding changing climate and environment and finding solutions; Hamburg, Germany, July 14-18, 2012. Hamburg, TuTech Innovation. 